\title{
Utilização da farinha de bacuri no desenvolvimento de bolo hiperproteico para esportistas: caracterização química e sensorial
}

\section{Use of bacuri flour in the development of hyperproteic cake for sportspersons: chemical and sensory characterization}

Utilización de la harina de bacuri en el desarrollo de pastel hiperproteico para deportistas: caracterización química y sensorial

\author{
Alberto Chidi Kawano ${ }^{1}$ \\ Elisvânia Freitas dos Santos ${ }^{2}$ \\ Fabiane La Flor Ziegler Sanches ${ }^{3}$
}

${ }^{1}$ Acadêmico de Nutrição da Faculdade de Ciências Farmacêuticas, Alimentos e Nutrição (Facfan) da Universidade Federal de Mato Grosso do Sul (UFMS). E-mail: albertokawano@hotmail.com, Orcid: http://orcid.org/0000-0002-0400-3845

${ }^{2}$ Doutora em Ciências da Cirurgia - Universidade Estadual de Campinas (Unicamp). Professora adjunta do Curso de Nutrição da Faculdade de Ciências Farmacêuticas, Alimentos e Nutrição (Facfan) da Universidade Federal de Mato Grosso do Sul (UFMS).E-mail: elisvania@gmail.com, Orcid: http://orcid.org/0000-0002-1528-6035

${ }^{3}$ Doutora em Alimentos e Nutrição - Universidade Estadual de Campinas (Unicamp). Professora adjunta do Curso de Nutrição da Faculdade de Ciências Farmacêuticas, Alimentos e Nutrição (Facfan) da Universidade Federal de Mato Grosso do Sul (UFMS).E-mail: fabianelaflor@gmail.com, Orcid: http://orcid.org/0000-0002-0096-3697 
Resumo: O objetivo foi desenvolver bolos hiperproteicos com diferentes concentrações de farinha da polpa de bacuri, determinar sua composição e realizar análise sensorial com esportistas. Elaboraram-se três formulações de bolos hiperproteicos: sem adição da farinha de bacuri (Padrão), adição de 35\% (F1) e adição de 50\% (F2). Foram realizadas análises de composição centesimal, sendo o teor de carboidrato determinado por diferença. A análise sensorial foi realizada com 80 provadores não treinados, adultos, esportistas, de ambos os sexos, utilizando escala hedônica. Considerou-se $p<0,05$. Resultados indicam que F1 e F2 apresentaram significativamente maiores teores de fibras em relação à Padrão. Não houve diferença significativa entre todas formulações no teor proteico e em nenhum dos atributos sensoriais, apresentando médias entre "gostei moderadamente" e "gostei muito". Quanto à aceitação global, os índices de aceitabilidade foram superiores a 75\%. A utilização da farinha de bacuri torna-se viável no desenvolvimento de produtos com frutos do Cerrado.

Palavras-chave: frutas; composição de alimentos, sensação; Ciências da Nutrição e do Esporte.

Abstract: The objective was to develop hyperproteic cakes with different concentrations
of bacuri pulp flour, determine its composition and perform sensory analysis with
sportspersons. We prepared three formulations of hyperproteic cakes: without the addition
of the bacuri flour (Standard), addition of $35 \%$ (F1), and addition of $50 \%$ (F2). We performed
an analysis of the centesimal composition, and the carbohydrate content was determined
by difference. We performed the sensory analysis with 80 untrained testers, adults,
sportspersons, of both sexes, using a hedonic scale. We considered p $<0.05$. Results indicate
that F1 and F2 presented significantly higher fiber contents than the Standard. There was
no significant difference between all formulations in the protein content and none of the
sensory attributes, presenting averages between "moderately liked" and "liked very much".
Regarding the overall acceptance, the acceptance rates were higher than $75 \%$. The use
of bacuri flour becomes viable in the development of products with fruits of the Cerrado.

Keywords: fruits; food composition; sensation; Sports Nutritional Sciences.

Resumen: El objetivo fue desarrollar pasteles hiperproteicos con diferentes concentraciones de harina de la pulpa de bacuri, determinar su composición y realizar análisis sensorial con deportistas. Se elaboraron tres formulaciones de pasteles hiperproteicos: sin adición de la harina de bacuri (Estándar), con adición de 35\% (F1) y adición de 50\% (F2). Se realizaron análisis de composición centesimal, siendo el contenido de carbohidrato determinado por diferencia. El análisis sensorial fue realizado con 80 probadores no entrenados, adultos, deportistas, de ambos sexos, utilizando escala hedónica. Se consideró $p<0,05$. Los resultados indican que F1 y F2 presentaron significativamente mayores contenidos de fibra en relación a la Estándar. No hubo diferencia significativa entre todas las formulaciones en el contenido proteico y en ninguno de los atributos sensoriales, presentando medias entre "me gustó moderadamente" y "me gustó mucho". En cuanto a la aceptación global, los índices de aceptabilidad fueron superiores al 75\%. La utilización de la harina de bacuri se hace viable en el desarrollo de productos con frutos del Cerrado.

Palabras clave: frutas; composición de alimentos; sensación; Ciencias de la Nutrición y del Deporte. 
Utilização da farinha de bacuri no desenvolvimento de bolo hiperproteico para esportistas:

\section{INTRODUÇÃO}

O bacuri (Attalea phalerata Mart. Ex Spreng), pertencente à família Arecaceae, sendo encontrado no Cerrado sul-mato-grossense, pode ser denominado localmente de acuri ou acurizeiro. A utilização do fruto pode resultar na elaboração de novos produtos alimentícios, contribuindo para o desenvolvimento econômico da região e valorização do fruto.

O consumo de alimentos regionais é recomendado pelo Guia Alimentar para a População Brasileira como uma das estratégias para a promoção da saúde; além disso, o guia "Alimentos Regionais Brasileiros", publicado pelo Ministério da Saúde, apresenta vários frutos das regiões brasileiras, destacando a importância e a valorização dos frutos locais.

Os esportistas e atletas têm uma maior preocupação com a alimentação, pois estão em busca de maior rendimento nos treinos e melhora da composição corporal. A procura de fontes alternativas de nutrientes se faz necessária à medida que há um constante aumento da demanda consumidora de suplementos nutricionais, em especial, os proteicos.

Nesse sentido, o bolo é um alimento amplamente aceito pela população em geral, sendo uma alternativa para atender à demanda por novos produtos com a utilização de frutos do Cerrado aliada à alimentação de esportistas.

Diante disso, o objetivo do trabalho foi desenvolver formulações de bolos hiperproteicos com diferentes concentrações de farinha da polpa de bacuri, determinar suas composições e avaliar a aceitabilidade sensorial entre o público de esportistas.

\section{MATERIAL E MÉTODOS}

Os frutos de bacuri (Attalea phalerata Mart. Ex Spreng) foram coletados em Campo Grande, em Mato Grosso do Sul, e transportados aos laboratórios da Unidade de Tecnologia de Alimentos e Saúde Pública da Universidade Federal de Mato Grosso do Sul (UFMS), onde as polpas foram retiradas e processadas para elaboração da farinha.

Os ingredientes das formulações de bolo hiperproteico foram obtidos no comércio local da cidade de Campo Grande. Foram utilizados: farinha 
de trigo (Rosa Branca ${ }^{\circledR}$ ), ovos, óleo $\left(\right.$ Soya $\left.{ }^{\circledR}\right)$, cacau em pó (Garoto ${ }^{\circledR}$ ), whey protein (G Suplementos ${ }^{\circledR}$ ), albumina (Naturovos ${ }^{\circledR}$ ), açúcar cristal (Estrela ${ }^{\circledR}$ ), leite desnatado (Italac $\left.{ }^{\circledR}\right)$, farinha da polpa de bacuri e fermento químico $\left(\right.$ Royal $\left.^{\circledR}\right)$.

\subsection{Formulação e técnica de preparo dos bolos}

Foram preparados três tipos de bolos hiperproteicos, sendo um deles denominado de Padrão, por não conter a farinha da polpa de bacuri, e os outros dois denominados de amostra F1 e amostra F2, contendo 35\% e 50\% de farinha de bacuri, respectivamente, em relação ao total de farinha. Os ingredientes supracitados em materiais foram utilizados na confecção dos bolos.

Foram colocados os ovos, óleo, leite desnatado, whey protein, albumina, farinha de trigo e da polpa de bacuri em um recipiente e, depois, transferidos para uma batedeira doméstica e misturados até formar uma massa homogênea. Logo em seguida, foi adicionado o fermento em pó e misturou-se novamente. Para não grudar a massa nas formas, estas foram untadas com óleo de soja e, assim, os bolos foram assados em forno preaquecido de 100 ㅇ C a 130 C, por 20 minutos. Após assados, os bolos foram resfriados em temperatura ambiente, embalados em papel-alumínio e porcionados no momento da análise sensorial.

\subsection{Análises físico-químicas}

As análises físico-químicas foram realizadas no Laboratório da Faculdade de Ciências Farmacêuticas, Alimentos e Nutrição (Facfan) da Universidade Federal de Mato Grosso do Sul. A farinha da polpa de bacuri, whey protein e as formulações de bolos hiperproteicos tiveram a composição química avaliada em triplicata. Os teores de umidade das amostras foram determinados por secagem em estufa a $105^{\circ} \mathrm{C}$, segundo método descrito na Analysis of Association of Official Analytical Chemists (AOAC, 2011). As quantificações de proteína foram feitas pelo conteúdo de nitrogênio total, segundo método de micro-Kjeldahl (AOAC, 2011). A determinação de cinzas foi realizada em mufla por meio do método da AOAC (2011). Os valores de lipídios foram avaliados pelo método de extração direta com éter de petróleo 
Utilização da farinha de bacuri no desenvolvimento de bolo hiperproteico para esportistas:

em aparelho de Soxhlet e a determinação de fibra dietética total foi realizada pelo método enzimático da AOAC (2011). O teor de carboidrato foi determinado por diferença, subtraindo-se de 100 a somatória dos demais teores.

\subsection{Análise sensorial}

A análise sensorial foi realizada em 80 provadores adultos, esportistas, ambos os sexos, não treinados, em uma academia de musculação da cidade de Campo Grande, MS, sendo consumidores potenciais do produto e selecionados em função da disponibilidade e do interesse em realizar os testes.

As amostras dos bolos foram apresentadas aos provadores em copos descartáveis codificados por três dígitos ao acaso, contendo cerca de $10 \mathrm{~g}$ de amostra por copo. Na ficha de avaliação sensorial, as amostras foram avaliadas em relação à aparência, textura, aroma, sabor, cor, intenção de compra e aceitação global (DUTCOSKY, 2011). Foi utilizada a escala hedônica estruturada de nove pontos ( 9 = gostei muitíssimo 8 = gostei muito; 7 = gostei moderadamente; 6 = gostei regularmente; 5 = nem gostei, nem desgostei; 4 = desgostei regularmente; 3 = desgostei moderadamente; 2 = desgostei muito 1 = desgostei muitíssimo) e solicitado que cada provador indicasse o que gostou e/ou desgostou na amostra. Para o teste de intenção de compra, foi usada escala hedônica estruturada de cinco pontos, variando desde a nota 5 (certamente compraria) até a nota 1 (certamente não compraria).

Os dados obtidos foram transformados em resultados por meio do cálculo do índice de aceitabilidade (IA) proposto por Monteiro (1984), descrito pela fórmula:

$$
\mathrm{A}(\%)=\mathrm{A} \times 100 / \mathrm{B}
$$

Onde: $A$ = nota média obtida para o produto; $B$ = nota máxima dada ao produto.

\subsection{Análise estatística}

Os dados foram analisados no software Statistical Package for the Social Sciences (SPSS). Os resultados foram submetidos à análise de variância ANOVA, sendo utilizado o teste de Tukey para confronto das médias, considerando um nível de $5 \%$ de significância $(p<0,05)$. 


\subsection{Aspectos éticos}

Este estudo foi encaminhado e aprovado pelo Comitê de Ética em Pesquisa da UFMS, sob parecer n. 2.305.728/2017.

\section{RESULTADOS E DISCUSSÃO}

\subsection{Formulações desenvolvidas}

Realizou-se a substituição parcial da farinha de trigo pela farinha da polpa de bacuri nas formulações F1 e F2. Inicialmente, nos pré-testes, foi utilizada uma concentração de $17,8 \%$ de farinha da polpa de bacuri, resultando em um bolo com aspecto ressecado, comprometendo, assim, sua textura. Nesse sentido, no decorrer dos testes preliminares, houve uma redução gradativa no teor da farinha da polpa de bacuri em substituição à farinha de trigo nas formulações. Para garantir maior umidade e maciez nos bolos, foram utilizados $12,84 \%$ e $9,88 \%$ de farinha de trigo e $6,91 \%$ e $9,86 \%$ da farinha da polpa de bacuri nas formulações F1 e F2, respectivamente. As concentrações de todos os ingredientes finais das formulações dos bolos avaliadas no presente estudo estão demonstradas na Tabela 1.

Tabela 1 - Formulações dos bolos com diferentes concentrações de farinha da polpa de bacuri, em \%

\begin{tabular}{lccc}
\hline \multicolumn{1}{c}{ Ingredientes } & Padrão (\%) & F1 (\%) & F2 (\%) \\
\hline Farinha de trigo & 19,75 & 12,84 & 9,88 \\
Farinha da polpa de bacuri & - & 6,91 & 9,86 \\
Leite desnatado & 17,11 & 17,11 & 17,11 \\
Ovos & 13,58 & 13,58 & 13,58 \\
Açúcar cristal & 23,62 & 23,62 & 23,62 \\
Óleo de soja & 12,58 & 12,58 & 13,58 \\
Cacau em pó & 7,55 & 7,55 & 7,55 \\
Whey protein & 3,46 & 3,46 & 3,19 \\
Albumina & 1,60 & 1,60 & 1,48 \\
Fermento em pó & 0,75 & 0,75 & 0,75 \\
\hline Total & $100 \%$ & $100 \%$ & $100 \%$ \\
\hline
\end{tabular}

Fonte: Autoria própria. 
Utilização da farinha de bacuri no desenvolvimento de bolo hiperproteico para esportistas:

\subsection{Análises físico-químicas}

Foram realizadas análises centesimais das fontes proteicas usadas para as formulações dos bolos hiperproteicos, whey protein e farinha da polpa de bacuri, para obtenção dos valores corretos para o cálculo final da composição e valor nutricional dos produtos desenvolvidos.

Na Tabela 2, constam os valores de umidade, cinzas, lipídeos, proteínas e carboidratos.

Tabela 2 - Composição centesimal do whey protein e da farinha da polpa de bacuri, em base úmida e base seca

\begin{tabular}{lccccc}
\hline \multirow{2}{*}{$\begin{array}{c}\text { Componentes } \\
\left(\mathbf{g} / \mathbf{1 0 0} \mathbf{~ g}^{\mathbf{1}}\right)\end{array}$} & \multicolumn{2}{c}{ Whey protein } & \multicolumn{2}{c}{ Farinha de bacuri } & \multirow{2}{*}{ p-valor* } \\
\cline { 2 - 5 } & BU & BS & BU & BS & \\
\hline Umidade & $3,34 \pm 0,205$ & - & $7,04 \pm 0,70$ & - & 0,0001 \\
Cinzas & $2,62 \pm 0,01$ & 2,71 & $3,96 \pm 0,05$ & 4,26 & 0,0001 \\
Lipídeos & $0,44 \pm 0,04$ & 0,45 & $13,98 \pm 0,09$ & 15,03 & 0,0001 \\
Proteínas $(\mathrm{N} \times \mathrm{F})^{1}$ & $76,45 \pm 1,75$ & 79,09 & $4,77 \pm 0,10$ & 5,13 & 0,0001 \\
Carboidrato $^{2}$ & $18,05 \pm 0,34$ & 12,46 & $70,25 \pm 0,67$ & 75,57 & 0,0001 \\
\hline
\end{tabular}

Valores médios das determinações em triplicata \pm desvio-padrão. BU: base úmida; BS: base seca. 1F: whey protein $=6,38$ e farinha da polpa de bacuri $=6,25$. 2Calculado por diferença $=100-$ (proteína + lipídios + cinzas + umidade + fibras). ${ }^{*}$ Teste de variância ANOVA-one way.

Fonte: Autoria própria.

De acordo com a Tabela 2, a composição do whey protein e da farinha da polpa de bacuri foi significativamente diferente $(p<0,05)$ em todos os nutrientes. A farinha da polpa de bacuri analisada apresentou $4,77 \%$ de proteína, valor superior quando comparado a 2,38\% de teor proteico encontrado na amostra de farinha da polpa de bacuri por Cunha et al. (2018). Em relação ao teor dos carboidratos, o valor encontrado no presente estudo foi de $70,25 \%$, sendo superior em relação aos valores da farinha de bacuri $(58,28 \%)$ e da farinha de bocaiuva $(35,75 \%)$ observados nos estudos de Cunha et al. (2018) e Kopper et al. (2009), respectivamente. O valor lipídico encontrado foi de $13,98 \%$, sendo superior quando comparado com outros frutos do Cerrado, como da farinha da casca do pequi $(11,37 \%)$ e da polpa do bacuri (11,83\%) (CARDOSO et al., 2014; CUNHA et al., 2018). 
Por meio do resultado da composição do whey protein (Tabela 2), foi feita uma comparação com o rótulo do produto comercializado (Tabela 3). Verificou-se que a amostra analisada apresenta pequena variação com o rótulo nutricional da embalagem do produto em relação à quantidade de proteína.

Tabela 3 - Comparação nutricional da composição centesimal do whey protein e as informações do rótulo nutricional do produto

\begin{tabular}{ccc}
\hline \multirow{2}{*}{ Componentes } & \multicolumn{2}{c}{ Quantidade em $\mathbf{3 0}$ g** } \\
\cline { 2 - 3 } & Whey Rótulo* & Whey Análise \\
\hline Valor energético (Kcal) & 114,0 & 113,41 \\
Carboidratos (g) & 4,5 & 5,42 \\
Proteínas (g) & 24,0 & 22,64 \\
Lipídios (g) & 0 & 0,13 \\
\hline
\end{tabular}

*Amostra comercial da marca G Suplementos ${ }^{\circledR}$.

**Porção de $30 \mathrm{~g}$, segundo o rótulo do produto.

Fonte: Autoria própria.

Nos estudos de Timoteo e Ferreira (2017), foram analisados cinco suplementos proteicos à base de proteína do soro de leite. Ao realizar a comparação das análises e dos rótulos das embalagens, observou-se incompatibilidade em todas as amostras. Em outro estudo, Lovato et al. (2014) analisaram quatro marcas de whey protein de empresas distintas e concluíram que uma marca estava acima do valor estabelecido pela legislação e as outras três marcas estavam abaixo do mínimo de $10 \mathrm{~g}$ de proteína por porção.

Os resultados da avaliação da composição das formulações dos bolos hiperproteicos estão apresentados na Tabela 4. 
Utilização da farinha de bacuri no desenvolvimento de bolo hiperproteico para esportistas:

Tabela 4 - Composição centesimal das formulações dos bolos hiperproteicos com diferentes concentrações de farinha da polpa de bacuri, em base úmida

\begin{tabular}{ccccc}
\hline $\begin{array}{c}\text { Componentes } \\
\left(\mathbf{g} / \mathbf{1 0 0} \mathbf{~ g}^{\mathbf{1}} \mathbf{)}\right.\end{array}$ & Padrão & F1 & F2 & p-valor* \\
\hline Umidade & $27,28 \pm 0,53^{\mathrm{a}}$ & $23,70 \pm 0,08^{\mathrm{b}}$ & $28,58 \pm 0,42^{\mathrm{a}}$ & 0,001 \\
Cinzas & $2,11 \pm 0,04^{\mathrm{a}}$ & $1,81 \pm 0,01^{\mathrm{b}}$ & $1,83 \pm 0,02^{\mathrm{b}}$ & 0,0001 \\
Lipídeos $^{\mathrm{p}}$ & $16,13 \pm 0,32^{\mathrm{b}}$ & $17,27 \pm 0,19^{\mathrm{a}}$ & $16,39 \pm 0,37^{\mathrm{b}}$ & 0,008 \\
Proteína (N X F) & $12,32 \pm 0,27^{\mathrm{a}}$ & $12,07 \pm 0,11^{\mathrm{a}}$ & $12,16 \pm 0,38^{\mathrm{a}}$ & 0,566 \\
Fibras & $0,76 \pm 0,13^{\mathrm{b}}$ & $3,08 \pm 0,75^{\mathrm{a}}$ & $3,99 \pm 0,44^{\mathrm{a}}$ & 0,004 \\
Carboidrato & $41,40 \pm 0,53$ & $42,07 \pm 0,42$ & $37,05 \pm 0,40$ & -- \\
Valor calórico & 360,05 & 371,99 & 344,35 & -- \\
(kcal/100 g) & & & & \\
\hline
\end{tabular}

Valores médios das determinações em triplicata \pm desvio-padrão. 1F: polpa e farinha $=6,25 .{ }^{2}$ Calculado por diferença $=100-$ (umidade + cinzas + lipídios + proteína + fibras). ${ }^{*}$ Teste de variância ANOVA-one way. Médias seguidas por letras iguais na mesma linha não diferem entre si pelo Post Hoc de Tukey a 5\% de probabilidade.

Fonte: Autoria própria.

Na composição centesimal das formulações dos bolos hiperproteicos com diferentes concentrações de farinha da polpa de bacuri, observou-se diferença significativa para todos os nutrientes, exceto para as proteínas. 0 teor de umidade foi inferior para a F1 em relação à F2 e Padrão. De acordo com Guimarães, Freitas e Silva (2010), os maiores valores de umidade foram encontrados nos bolos com fibra alimentar, devido à propriedade das fibras de reter água em sua estrutura durante o processo de cocção, o que não foi verificado no presente estudo, uma vez que F1 e F2 apresentaram teores de fibra significativamente superiores aos da formulação Padrão.

A formulação F2 apresentou maior teor de lipídeos em relação as demais, uma vez que nas formulações dos bolos utilizou-se óleo de soja, além da quantidade presente nos demais ingredientes. Por outro lado, na pesquisa de Cunha et al. (2018), os autores desenvolveram barras de cereais com acréscimo de $10 \%$ e $20 \%$ de farinha da polpa de bacuri, assim, os valores encontrados foram de 3,29\% e 5,24\% de lipídeos, respectivamente.

Na pesquisa de Perez e Germani (2007), os autores adicionaram ingredientes fontes de fibras em suas formulações de biscoitos salgados, 
resultando na diminuição de carboidratos à medida que se aumentava a concentração da farinha de berinjela que substituía a farinha de trigo. No presente estudo, o conteúdo de carboidratos se apresentou semelhança entre todas as formulações, independentemente dos seus teores de fibras.

Em relação à proteína, as três amostras apresentaram valores parecidos, não havendo diferença estatística entre elas. De acordo com a RDC n. 54, de 2012, da Anvisa (BRASIL, 2012), um alimento pode ter a classificação como fonte ou alto conteúdo de proteína. Para ser fonte, o alimento necessita ter no mínimo 6 gramas de proteína por porção. Já para o alimento ser considerado com alto conteúdo de proteína, necessita ter no mínimo 12 gramas de proteína por porção; assim, as três formulações (Padrão, F1, F2) podem ser consideradas de alto conteúdo de proteína, de acordo com a legislação vigente.

$\mathrm{Na}$ Tabela 5, foram realizadas as comparações entre as três formulações do presente trabalho e um bolo de laranja comercial. Pode-se notar que o conteúdo proteico e lipídico das formulações Padrão, F1 e F2 apresentaram quantidades maiores do que os teores do bolo comercial, entretanto a quantidade de carboidratos foi, aproximadamente, $50 \%$ inferior nas formulações desenvolvidas, quando comparadas com a composição do bolo comercial. Esses resultados contribuíram para os valores energéticos inferiores nos bolos hiperproteicos elaborados no presente estudo.

Tabela 5 - Comparação nutricional das formulações de bolos hiperproteicos com diferentes concentrações de farinha de bacuri e as informações do rótulo de bolo comercializado

\begin{tabular}{ccccc}
\hline \multirow{2}{*}{ Componentes } & \multicolumn{4}{c}{ Quantidade em 37 g** } \\
\cline { 2 - 5 } & $\begin{array}{c}\text { Bolo } \\
\text { Comercial* }\end{array}$ & $\begin{array}{c}\text { Bolo } \\
\text { Padrão }\end{array}$ & $\begin{array}{c}\text { Bolo } \\
\text { F1 }\end{array}$ & $\begin{array}{c}\text { Bolo } \\
\text { F2 }\end{array}$ \\
\hline Valor energético (Kcal) & 158,00 & 133,25 & 137,67 & 127,38 \\
Carboidratos (g) & 31,00 & 15,32 & 15,57 & 13,71 \\
Proteínas (g) & 1,40 & 4,56 & 4,47 & 4,50 \\
Lipídios (g) & 3,10 & 5,97 & 6,39 & 6,06 \\
\hline
\end{tabular}

*Amostra comercial da marca Dona Benta ${ }^{\circledR}$. **Porção de 37 g, segundo o rótulo da marca comercial Dona Benta ${ }^{\circledR}$.

Fonte: Autoria própria. 
Utilização da farinha de bacuri no desenvolvimento de bolo hiperproteico para esportistas:

\subsection{Análise sensorial}

O perfil dos provadores foi traçado a partir das informações contidas na ficha de avaliação. A participação foi de 40 indivíduos do sexo feminino (50\%) e 40 do sexo masculino (50\%). Verificou-se que 60\% dos participantes já consumiam whey protein e que $40 \%$ não conheciam o fruto bacuri.

Figura 1 - Percentual de provadores $(n=80)$ que mais gostaram de cada formulação do bolo hiperproteico

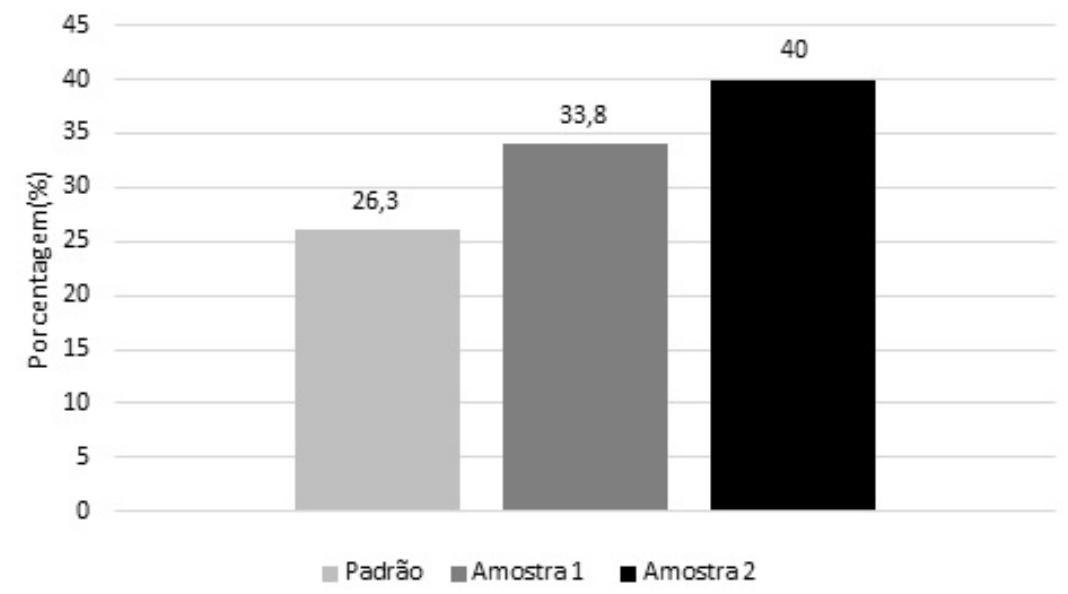

Fonte: Autoria própria.

De acordo com a Figura 1, em ordem decrescente, os participantes que mais gostaram foram: $40 \%(n=32)$, amostra $2(F 2) ; 33,8 \%(n=27)$, amostra 1 (F1); e 26,3\% ( $n=21)$ da amostra Padrão. 
Figura 2 - Percentual de provadores $(n=80)$ que menos gostaram de cada formulação do bolo hiperproteico

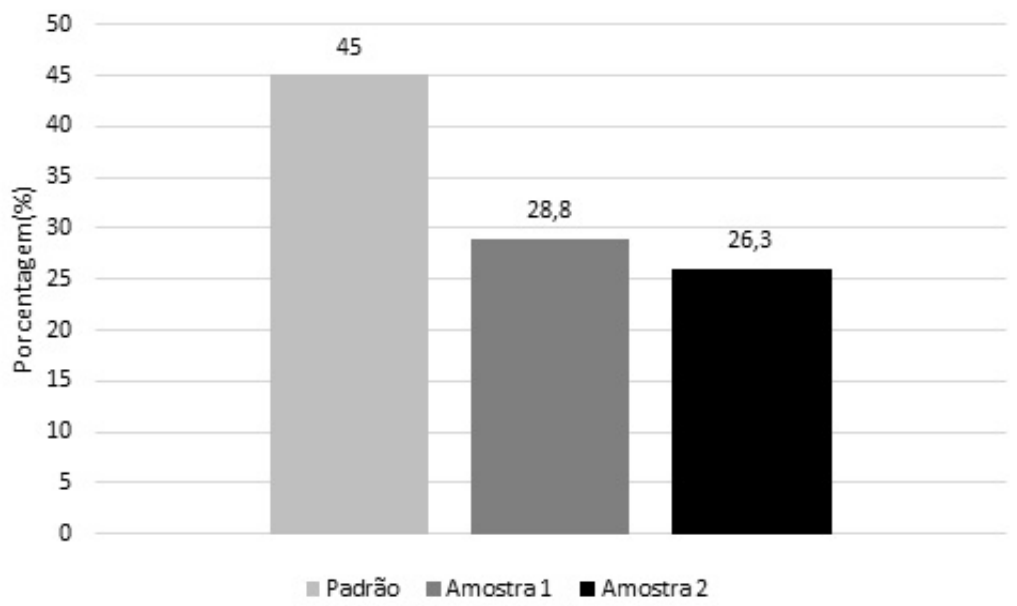

Fonte: Autoria própria.

A Figura 2 representa o percentual dos entrevistados que menos gostaram das formulações avaliadas, sendo que $45 \%(n=36)$ não gostaram da amostra Padrão, 28,8\% ( $n=23$ ) não gostaram da amostra F1 e 26,3\% ( $n$ = 21) não gostaram da amostra F2.

Na Tabela 6, estão demonstradas as médias dos atributos sensoriais realizados com os respectivos índices de aceitabilidade.

Tabela 6 - Médias dos testes sensoriais afetivos de aceitação e intenção de compra e índice de aceitabilidade realizados para as formulações de bolos hiperproteicos Padrão, F1 e F2

\begin{tabular}{ccccc}
\hline $\begin{array}{c}\text { Formulações / } \\
\text { Atributos }\end{array}$ & $\begin{array}{c}\text { Padrão } \\
\text { Média } \pm \text { DP }\end{array}$ & $\begin{array}{c}\text { F1 } \\
\text { Média } \pm \text { DP }\end{array}$ & $\begin{array}{c}\text { F2 } \\
\text { Média } \pm \text { DP }\end{array}$ & p-valor* \\
\hline Aparência & $7,14 \pm 1,22$ & $7,44 \pm 1,34$ & $7,51 \pm 1,18$ & 0,634 \\
IA (\%) & 79,34 & 82,67 & 83,45 & \\
Textura & $7,15 \pm 1,54$ & $7,16 \pm 1,90$ & $7,45 \pm 1,48$ & 0,304 \\
IA (\%) & 79,45 & 79,56 & 82,78 & \\
Aroma & $7,35 \pm 1,49$ & $7,39 \pm 1,49$ & $7,31 \pm 1,61$ & 0,634 \\
IA (\%) & 81,67 & 82,12 & 81,23 &
\end{tabular}




\begin{tabular}{ccccc}
\hline $\begin{array}{c}\text { Formulações / } \\
\text { Atributos }\end{array}$ & $\begin{array}{c}\text { Padrão } \\
\text { Média } \pm \text { DP }\end{array}$ & $\begin{array}{c}\text { F1 } \\
\text { Média } \pm \text { DP }\end{array}$ & $\begin{array}{c}\text { F2 } \\
\text { Média } \pm \text { DP }\end{array}$ & p-valor* \\
\hline Sabor & $7,15 \pm 1,37$ & $7,50 \pm 1,43$ & $7,63 \pm 1,18$ & 0,067 \\
IA (\%) & 79,45 & 83,34 & 84,78 & \\
Cor & $8,00 \pm 1,03$ & $8,10 \pm 1,01$ & $7,96 \pm 1,27$ & 0,721 \\
IA (\%) & 88,89 & 90,00 & 88,45 & \\
Doçura & $7,36 \pm 1,55$ & $7,60 \pm 1,53$ & $7,69 \pm 1,37$ & 0,357 \\
IA (\%) & 81,78 & 84,45 & 85,45 & \\
Aceitação Global & $7,14 \pm 1,22$ & $7,44 \pm 1,34$ & $7,51 \pm 1,18$ & 0,135 \\
IA (\%) & 79,34 & 82,67 & 83,45 & \\
Intenção de Compra & $3,76 \pm 1,01$ & $3,89 \pm 1,26$ & $4,01 \pm 0,92$ & 0,304 \\
IA (\%) & 75,2 & 77,8 & 80,2 & \\
\hline
\end{tabular}

DP: desvio-padrão; Padrão: 0\% de farinha da polpa de bacuri; F1: 35\% de farinha da polpa de bacuri e F2 50\% de farinha da polpa de bacuri; IA: Índice de Aceitabilidade. Teste de variância ANOVA-one way.

Fonte: Autoria própria.

Não houve diferença estatística significativa para nenhum dos atributos sensoriais avaliados na comparação das médias das formulações F1, F2 e padrão, apresentando valores médios na escala hedônica entre "gostei moderadamente" e "gostei muito". No parâmetro sabor, as formulações padrão, F1 e F2 obtiveram médias de 7,15, 7,50 e 7,63 e, para a aparência, médias de 7,58, 7,41 e 7,35, respectivamente.

Quanto à aceitação global, os índices de aceitabilidade foram de 79,34\%, $82,67 \%$ e $83,45 \%$ e, para a intenção de compra, de $75,2 \%$, 77,8\% e 80,2\%, para as amostras padrão, F1 e F2, respectivamente. No estudo de Cunha et al. (2018), em que avaliaram sensorialmente barras de cereais enriquecidas com adição de $10 \%$ (F2) e $20 \%$ (F3) de farinha da polpa de bacuri, os autores obtiveram o maior índice de intenção de compra para F2, com valor de 4,31, resultando em ótima aceitabilidade sensorial, assim como ocorreu no presente estudo.

De acordo com os resultados da Tabela 6, a aceitação global das formulações F1 e F2 apresentou índices acima de 80\%, evidenciando que a substituição da farinha de bacuri pela farinha branca foi satisfatória, não promovendo alterações indesejáveis. Entretanto, nos resultados do estudo de Ozores, Storck e Fogaça (2015), que formularam quatro tipos de bolos enriquecidos 
com farinha de maracujá, pôde-se observar aceitabilidade desejável dos bolos com adição de $5 \%$ e $10 \%$ da farinha de maracujá, porém, quando a quantidade foi aumentada para 20\%, a aceitabilidade para todos os atributos sensoriais avaliados diminuiu significativamente.

Segundo Dutcosky (2011), uma amostra é considerada bem-aceita quando apresentar um índice de aceitabilidade (IA) maior ou igual a 70\%. A adição de farinha de bacuri não alterou o índice de aceitabilidade dos bolos hiperproteicos, pois todas as formulações apresentaram IA acima de 70\% em todos os atributos sensoriais avaliados.

\section{CONCLUSÃO}

A adição da farinha da polpa de bacuri ao bolo hiperproteico demonstrou ser uma alternativa favorável para elaboração de bolos, visto que não houve diferença sensorial com a formulação padrão, além de apresentar vantagens nutricionais na sua composição.

Assim, a utilização da farinha de bacuri torna-se viável do ponto de vista tecnológico, nutricional e sensorial no desenvolvimento de produtos com frutos do Cerrado voltados para o público esportista, buscando fontes proteicas vegetais alternativas, como o caso do bacuri, fruto nativo encontrado amplamente em Mato Grosso do Sul.

\section{REFERÊNCIAS}

ANALYSIS OF ASSOCIATION OF OFFICIAL ANALYTICAL CHEMISTS. Official Methods of Analysis of Association of Official Analytical Chemists. 18. ed.; 4. rev. Gaithersburg, MD: AOAC, 2011.

BRASIL. Agência Nacional de Vigilância Sanitária (Anvisa). Resolução RDC n. 54, de 12 de novembro de 2012. Regulamento técnico sobre informação nutricional complementar. Diário Oficial da União, Brasília, 13 de novembro de 2012. Seção 1, p. 122. Disponível em: http://portal.anvisa.gov.br/documents/\%2033880/2568070/ rdc0054_12_11_2012.pdf/c5ac23fd-974e-4f2c-9fbc-48f7e0a31864. Acesso em: 22 abr. 2018.

CARdoso, A. E. A.; ZANelato, E. F. N.; ViAnA, E. S. M.; MOReiRA, A. P. B.; CARDOSO, L. M. Características físico-químicas da farinha da casca do pequi 
Utilização da farinha de bacuri no desenvolvimento de bolo hiperproteico para esportistas: caracterização química e sensorial

(Caryocar brasiliense Camb.) e seu aproveitamento na elaboração de barras de cereais. In: Anais VI Simpac, v. 6, n. 1, p. 209-14, jan./dez. 2014. Disponível em: https://academico.univicosa.com.br/revista/index.php/RevistaSimpac/article/ download/449/592. Acesso em: 20 ago. 2018.

CUNHA, F. C. C.; SIQUEIRA, I. F. S.; PELEGRIN, J. O.; SOUZA, A. V. O. M.; VASCONCELOS, M. P.; JORDÃO, C.; SANTOS, E. F.; HIANE, P. A.; SANCHES, F. L. F. Z. Development of cereal bars using bacuri pulp flour for sportsmen: nutritional composition and sensory acceptability. International Journal of Development Research, v. 8, n. 2, p. 18947-53, fev. 2018. Disponível em: https://www.journalijdr.com/sites/default/ files/issue-pdf/12069.pdf. Acesso em: 21 jul. 2018.

DUTCOSKY, S. D. Análise sensorial de alimentos. Curitiba: Champagnat, 2011.

GUIMARÃES, R. R.; FREITAS, M. C. J.; SILVA, V. L. M. Bolos simples com farinha entrecasca de melancia (Citrullus vulgaris, sobral): avaliação química, física e sensorial. Ciência e Tecnologia de Alimentos, Campinas, SP, v. 30, n. 2, p. 354-63, abr./jun. 2010. Disponível em: http://www.scielo.br/pdf/cta/v30n2/11.pdf. Acesso em: 15 jun. 2018.

KOPPER, A. G.; SARAVIA, A. P. K.; RIBANI, R. H.; LORENZI, G. M. A. C. Utilização tecnológica da farinha de bocaiuva na elaboração de biscoitos tipo cookie. Alimentos e Nutrição, Araraquara, SP, v. 20, n. 3, p. 463-9, jul./set. 2009. Disponível em: http:// serv-bib.fcfar.unesp.br/seer/index.php/alimentos/article/view/1149/844. Acesso em: 12 jul. 2018.

LOVATO, F.; KOWALESKI, J.; SANTOS, L. R.; SILVA, S. Z. Avaliação da conformidade de suplementos alimentares frente a legislação vigente. Revista Brasileira de Nutrição Esportiva, São Paulo, v. 8, n. 47, p. 330-5, set./out. 2014. Disponível em: http://www. rbne.com.br/index.php/rbne/article/view/472/438. Acesso em: 22 maio 2018.

MONTEIRO, C. L. B. Técnicas de Avaliação sensorial. 2. ed. Curitiba: Universidade Federal do Paraná: CEPPA, 1984. 101 p.

OZORES, B.; STORCK, C. R.; FOGAÇA, A. O. Aceitabilidade e características tecnológicas de bolo enriquecido com farinha de maracujá. Disciplinarum Scientia, Santa Maria, RS, v. 16, n. 1, p. 61-9, 2015. Disponível em: https://www.periodicos.unifra.br/index. php/disciplinarumS/article/view/1110/1052. Acesso em: 7 ago. 2018.

PEREZ, P. M. P.; GERMANI, R. Elaboração de biscoito tipo salgado, com alto teor de fibra alimentar, utilizando farinha de berinjela (Solanum melongena, L.). Ciências 
e Tecnologia de Alimentos, Campinas, SP, v. 27, n. 1, p. 186-92, jan./mar. 2007. Disponível em: http://www.scielo.br/pdf/cta/v27n1/32.pdf. Acesso em: 11 jul. 2018.

TIMOTEO, R. G.; FERREIRA, M. C. M. Análise do teor de macronutrientes em suplementos dietéticos tipo whey protein. Revista Iniciare, Campo Mourão, PR, v. 2, n. 1, p. 96-107, jan./jun. 2017. Disponível em: http://revista2.grupointegrado. br/revista/index.php/iniciare/article/view/2504/928. Acesso em: 30 maio 2018. 